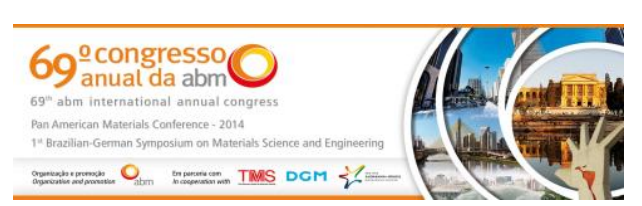

Tema: Mecânica de fratura e integridade estrutural

\title{
ANÁLISE DA FRATURA E DAS TENSÕES TÉRMICAS NO LINGOTAMENTO DE SILÍCIO*
}

Virgínia Cruz Rangel Albuquerque e Lima' André Alexandrino Lotto²

\section{Resumo}

Nas últimas décadas, o silício grau solar ( 99,9999\% de pureza) tornou-se um importante material devido à sua aplicação na construção de células fotovoltaicas. $O$ comportamento frágil do silício a temperatura ambiente dificulta a obtenção de formatos convenientes para as etapas posteriores de processamento. $O$ presente trabalho tem o objetivo de analisar a fratura de lingotes de silício ocorrida durante 0 processo de lingotamento contínuo após fusão em forno de feixe de elétrons. A análise do silício obtido no lingotamento contínuo mostrou a ocorrência de fratura por clivagem. A fratura observada após o lingotamento de iniciadores de silício ocorreu na mesma região do lingote obtido no lingotamento contínuo, indicando que a força aplicada para extração do silício durante o lingotamento contínuo não causa a fratura, que, portanto resulta das tensões térmicas durante a solidificação e resfriamento posterior. A modelagem matemática através do método dos elementos finitos da transferência de calor combinada com a formação de tensões térmicas mostrou que as tensões térmicas resultantes do processo de resfriamento, após a solidificação, poderiam ser suficientes para causar as fraturas observadas.

Palavras-chave: Lingotamento contínuo de silício; Fratura frágil; Método dos elementos finito; Tensões térmicas.

\section{ANALYSIS OF FRACTURE AND THERMAL STRESS IN SILICON CASTING Abstract}

In recent decades, the solar-grade silicon ( 99.9999\% purity) has become an important material due to its application in the construction of photovoltaic cells. The brittle behavior of silicon at room temperature difficult to obtain convenient shapes for subsequent processing steps. This study aims to analyze the fracture of silicon ingots occurred during the continuous casting process after melting in electron beam furnace. The analysis of silicon obtained in the continuous casting showed the occurrence of fracture cleavage. The fracture observed after casting starter silicon occurred in the same region of the ingot obtained in continuous casting, indicating that the force applied to extract the silicon during the continuous casting does not cause the fracture, which therefore results from thermal stresses during solidification and subsequent cooling. Mathematical modeling by the finite element method of heat transfer combined with the formation of thermal stresses showed that thermal stresses resulting from the cooling process after solidification could be sufficient to cause fractures observed.

Keywords: Continuous casting of silicon; Brittle fracture; Finite element method; Thermal stresses.

1 Engenheira de Materiais, Departamento de Engenharia Metalúrgica e de Materiais, Escola Politécnica da Universidade de São Paulo, São Paulo, SP, Brasil.

2 Engenheiro de Materiais, Pesquisador Assistente, Centro Tecnológico de Metalurgia e Materiais (CTMM), Instituto de Pesquisas Tecnológicas (IPT), São Paulo, SP, Brasil.

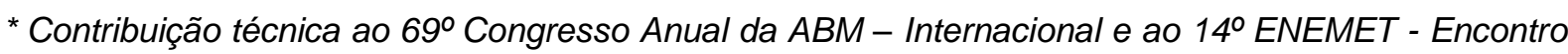
Nacional de Estudantes de Engenharia Metalúrgica, de Materiais e de Minas, 21 a 25 de julho de 2014, São Paulo, SP, Brasil. 


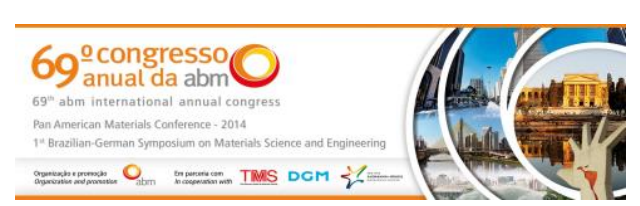

\section{INTRODUÇÃO}

A conscientização de todos em relação aos problemas ambientais do planeta tem pressionado governos de muitos países a reduzirem as emissões de gases que contribuem para o chamado efeito estufa. No entanto, a redução das emissões significa também frear o crescimento econômico. Uma possível solução seria produção de energia elétrica a partir da energia solar. As células solares utilizam o silício de grau solar (Si-GS) que possui 99,999 a 99,9999\% de pureza. O refino de silício pode ser realizado por duas rotas: química ou metalúrgica. A rota química é capaz de produzir silício de elevadíssima pureza (Si- GE- 99,9999999\%), mas é uma rota cara que não consegue atender a demanda do crescente mercado de células solares. A rota metalúrgica produz Si-GS a partir do silício grau metalúrgico (Si-GM), que possui pureza de 99 a 99,5\%, através de uma sequência de etapas de refino que envolve processos de lixiviação, escorificação e solidificação.

O lingotamento contínuo de silício em forno de feixe de elétrons é uma técnica pouco estudada, mas que algum dia poderá integrar o conjunto de etapas de refino e conformação de Si-GS da rota metalúrgica. Os objetivos da técnica são: a remoção de fósforo por evaporação durante o lingotamento contínuo, o refino de impurezas metálicas por solidificação direcional e facilitar o corte de wafers para a fabricação das células solares. O lingotamento contínuo de silício em forno de feixe de elétrons consiste na fusão do silício pelo feixe em um suporte de cobre refrigerado com água. Após a fusão total do silício, inicia-se a alimentação com grânulos de silício e o deslocamento do suporte de cobre. Um cristalizador de cobre também refrigerado a água serve como molde. $O$ processo de fusão ocorre no vácuo no interior da câmara do forno. A Figura 1 mostra um esquema do forno de feixe de elétrons durante o processo de lingotamento contínuo.

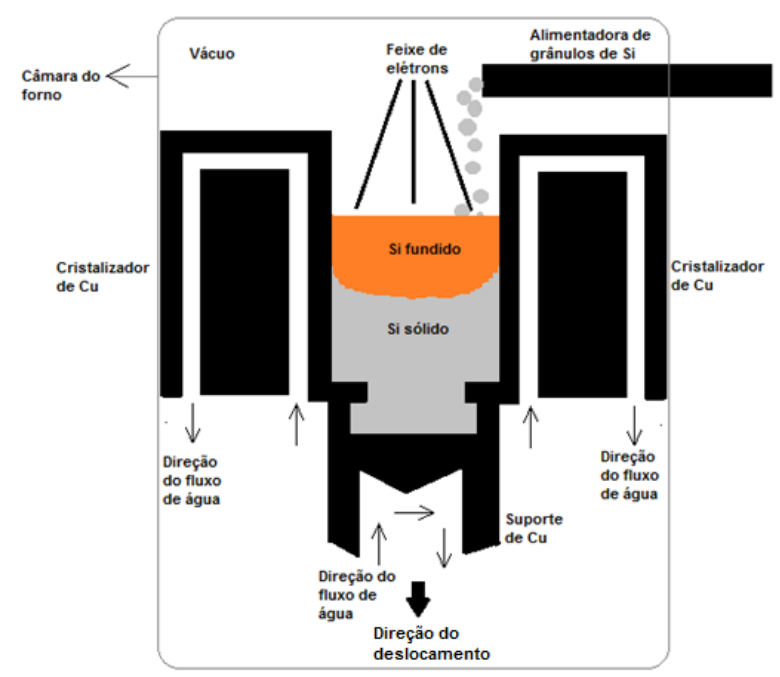

Figura 1. Esquema do forno de feixe de elétrons.

O princípio básico do refino ao vácuo é a diferença de pressão de vapor de componentes metálicos líquidos a elevadas temperaturas [1]. Já o refino por solidificação direcional se baseia na macrosegregação de soluto, devido à diferença de solubilidade de impurezas no silício no estado líquido e no estado sólido. O grau de purificação depende tanto das propriedades termodinâmicas do silício, no estado

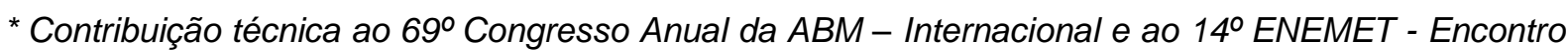
Nacional de Estudantes de Engenharia Metalúrgica, de Materiais e de Minas, 21 a 25 de julho de 2014, São Paulo, SP, Brasil.
} 
liquido e sólido, como das propriedades termodinâmicas das impurezas presente inicialmente no silício líquido [1].

As fraturas frágeis possuem certas características que permitem serem identificadas corretamente, as quais são: ausência de deformação plástica na região da fratura; superfície da fratura é perpendicular à força de tração; marcas características sobre a superfície da fratura frequentemente apontam para o local da origem da trinca [2].

A trinca de fratura frágil geralmente pode-se propagar por duas maneiras diferentes: clivagem ou fratura intergranular. As fraturas por clivagem, também conhecidas como transgranular ou transcristalina, são caracterizadas pela divisão dos cristais ou grãos ao longo de um plano cristalográfico específico sem respeitar os contornos de grão [2]. A fratura intergranular é aquela que segue o contorno de grão, enfraquecido por alguma razão [2]. O silício tem uma tendência para clivar ao longo de planos cristalográficos, principalmente quando cantos, superfícies ou defeitos causam tensões concentradas e orientadas ao longo de planos de clivagem [3]. O silício possui temperatura de transição dúctil-frágil em torno de $500^{\circ} \mathrm{C}$ [4]. Abaixo dessa temperatura o silício tem comportamento completamente frágil e fratura por clivagem [4]. A resistência à fratura do Si-GE em temperaturas abaixo de $500{ }^{\circ} \mathrm{C}$ está entre 1 e $20 \mathrm{GPa}$ e depende do tamanho do defeito, do modo de carregamento, da orientação da microestrutura, do tamanho da amostra e do método de teste [4]. Para o silício com grau de pureza mais baixo que o eletrônico, a resistência à fratura deve ser menor que $1 \mathrm{GPa}$, porque a maior quantidade de impurezas localizadas no contorno de grão fragiliza o material.

O critério de ruptura de materiais frágeis pode ser determinado pela teoria de Rankine, no qual a fratura ocorre quando o limite de resistência obtido para o material em ensaios uniaxiais de tração é superado pela máxima tensão principal de tração no estado de tensões analisado [5].

$O$ método de elementos finitos, MEF, consiste em uma técnica de soluções numéricas aproximadas que considera um malha ou uma rede de elementos finitos, de geometria simples, nos quais as força internas devem estar em equilíbrio em determinados pontos compartilhados por vários elementos, os quais recebem 0 nome de nós [6].

Este trabalho concentrou seus esforços na produção de lingotes de silício por lingotamento contínuo em forno de feixe de elétrons. O objetivo da técnica é a remoção principalmente do fósforo por destilação no vácuo durante o lingotamento contínuo e o refino por solidificação direcional de impurezas metálicas durante a solidificação dos lingotes, além de facilitar o corte de wafers para a fabricação das células solares. No entanto, fraturas recorrentes durante o processo de lingotamento contínuo, limita o tamanho dos lingotes obtidos.

\section{MATERIAIS E MÉTODOS}

No lingotamento contínuo de silício utilizou-se um forno de feixe de elétrons do Instituto de Pesquisas Tecnológicas (IPT). A Figura 2a mostra uma visão externa da câmara do forno e a Figura $2 b$ mostra a lingoteira localizada abaixo do forno que é conectada ao fundo da câmara. Utilizou-se um cristalizador de $60 \mathrm{~mm}$ de diâmetro, uma alimentadora de grânulos de Si-GM (Figura 2c) e um suporte de cobre (Figura 2d). A pressão na câmara do forno é da ordem de $10^{-4} \mathrm{~Pa}$. A Tabela 1 mostra as condições para cada corrida de lingotamento contínuo.

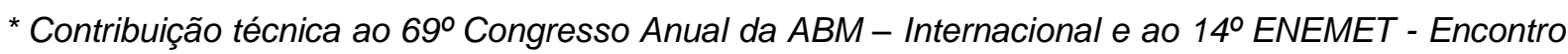
Nacional de Estudantes de Engenharia Metalúrgica, de Materiais e de Minas, 21 a 25 de julho de 2014, São Paulo, SP, Brasil.
} 


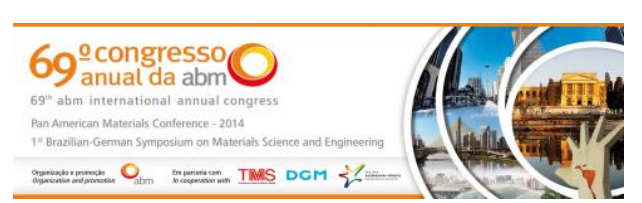

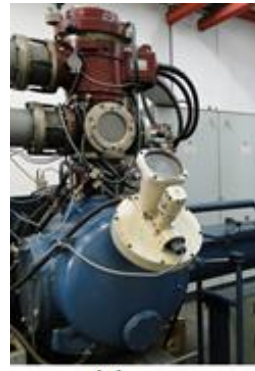

(a)

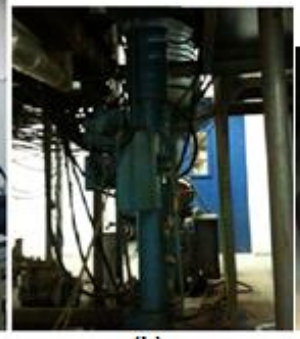

(b)

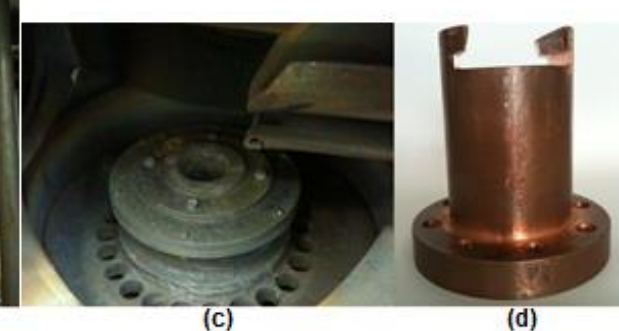

(d)

Figura 2. Forno de feixe de elétrons do IPT. (a) Parte superior do forno, visão externa da câmara do forno e da alimentadora de grânulos. (b) Parte inferior do forno, lingoteira conectada ao fundo da câmara do forno. (c) Cristalizador de $60 \mathrm{~mm}$ de diâmetro e a alimentadora de grânulos localizada acima do cristalizador. (d) suporte de cobre.

Tabela 1: Condições para cada corrida de lingotamento contínuo

\begin{tabular}{cccccc}
\hline Corrida & $\begin{array}{c}\text { Potência do } \\
\text { feixe }(\mathbf{k W})\end{array}$ & Pintura & Iniciador & $\begin{array}{c}\text { Material } \\
\text { do } \\
\text { iniciador }\end{array}$ & Alimentação \\
\hline EB43 & 20 & Não & Não & -------- & Si-GM \\
\hline EB44 & 20 & Não & Não & ------- & Si-GM \\
\hline EB46 & 20 & Sim & Sim & Si-GM & Si-GM \\
\hline EB47 & 20 & Sim & Sim & Si-GE & Si-GM \\
\hline EB48 & 20 & Sim & Sim & Si-GE & Si-GM \\
\hline
\end{tabular}

As duas primeiras corridas, EB43 e EB44, não tiveram a parede do cristalizador pintada com nitreto de silício, $\mathrm{Si}_{3} \mathrm{~N}_{4}$. Essas duas corridas foram realizadas apenas com Si-GM. Inicialmente, carregou-se o suporte de cobre com Si-GM e fechou-se a câmara. Quando uma pressão da ordem de $10^{-4} \mathrm{~Pa}$ foi atingida no interior da câmara, o feixe foi ligado e iniciou-se a fusão do silício depositado no suporte de cobre. Quando o silício depositado estava totalmente fundido, iniciou-se, simultaneamente, o carregamento com grânulos de Si-GM e o deslocamento para baixo do suporte de cobre, a uma velocidade de aproximadamente $4 \mathrm{~mm} / \mathrm{min}$. Tentou-se atingir o estado estacionário, no qual o nível de silício fundido no cristalizador se mantem constante. A corrida terminou quando o nível de silício no cristalizador começou aumentar. Isso indica que houve a ruptura do lingote, ou seja, o lingote não está mais conectado ao suporte de cobre que continua descendo. Neste instante, o feixe de elétrons foi desligado e iniciou-se a solidificação do material que ainda está líquido. Nas três seguintes corridas (EB 46, EB47 e EB48), a parede do cristalizador foi pintada com $\mathrm{Si}_{3} \mathrm{~N}_{4}$ para diminuir o atrito entre a parede do cristalizador e a parede do lingote de silício durante o lingotamento contínuo. Após a pintura, o cristalizador foi colocado em uma estufa para que a água fosse evaporada. Depois da secagem, o cristalizador foi recolocado na câmara do forno. Nas corridas EB46, EB47 e EB48, um iniciador de silício foi fundindo no suporte de cobre, antes do início do processo de lingotamento. Na corrida EB46, o iniciador foi produzido com silício de grau metalúrgico. Nas corridas EB47 e EB48, ambos os iniciadores foram feitos de silício grau eletrônico. Na fundição de um iniciador de silício de grau eletrônico (Si-GE) no suporte de cobre, a parede do cristalizador foi pintada com uma solução de $\mathrm{Si}_{3} \mathrm{~N}_{4}$. Após a pintura e a secagem, o cristalizador foi recolocado na câmara do forno. Em seguida, o forno foi carregado com uma quantidade suficiente de Si-GE para cobrir todo o suporte de cobre. O silício

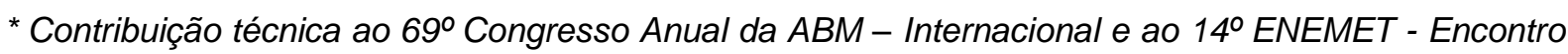
Nacional de Estudantes de Engenharia Metalúrgica, de Materiais e de Minas, 21 a 25 de julho de 2014, São Paulo, SP, Brasil. 


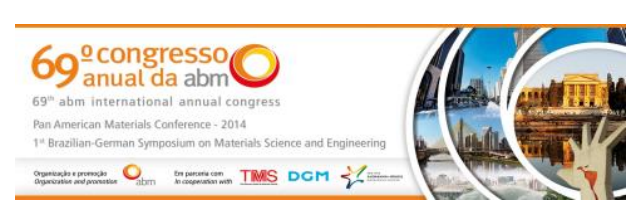

depositado no suporte de cobre foi completamente fundido pelo feixe de elétrons a uma tensão de $20 \mathrm{kV}$, a uma pressão de 0,0002 Pa, aproximadamente. Após a fusão total do material, o feixe foi desligado e iniciou-se a solidificação.

$\mathrm{Na}$ preparação da macrografia, o lingote EB48 foi cortado longitudinalmente ao meio, lixado, lavado com água e atacado com $\mathrm{NaOH}$. Na micrografia, a outra metade do lingote EB48 foi cortada longitudinalmente ao meio, lixada e polida. Após a preparação metalográfica, a amostra foi lavada com acetona e secada. Para o MEV da superfície da fratura do lingote da corrida EB46, um corte transversal no lingote EB46, perto da região da fratura, foi feito em uma serra de fita. O pedaço que continha a superfície da fratura foi lavado e secado. Depois de limpo, depositou-se ouro na superfície da fratura para aumentar a condutividade do silício.

Para preparar os fragmentos da corrida EB43 e EB44 para a análise química, as amostras são desengorduras em um recipiente com acetona em um ultrassom. Depois, as amostras são retiradas do recipiente, lavadas com acetona e secadas em uma estufa. Em seguida, elas são quebradas manualmente em um recipiente metálico que passou por um processo de descontaminação. As amostras são analisadas pela técnica de espectrometria de emissão óptica com plasma indutivamente acoplado, ICP-OES.

Para simular a solidificação e as tensões térmicas após a solidificação de um iniciador de silício, inicialmente foi feito um desenho no CAD do cristalizador de cobre, do suporte de cobre e do iniciador de silício (Figura 3) e uma estimativa da temperatura do silício líquido, já que a temperatura do silício líquido não pode ser medida diretamente.
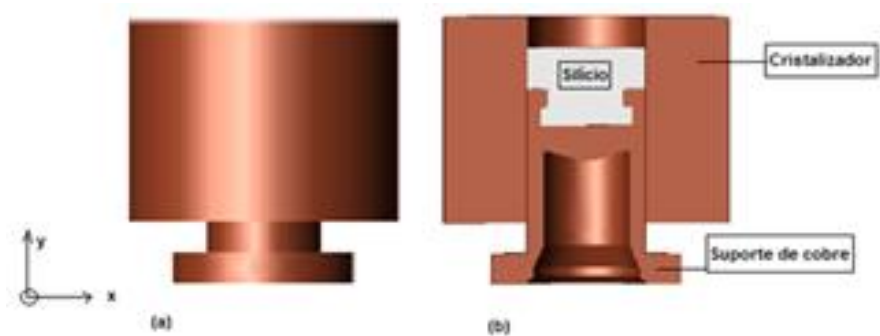

Figura 1. Desenho do CAD do cristalizador de cobre, suporte de cobre e do silício. (a) vista frontal sem corte e (b) vista frontal com um corte no plano XY.

Na simulação da evolução da temperatura de solidificação de um iniciador de silício considerou-se que a temperatura inicial de todo o fundido era de $1827^{\circ} \mathrm{C}(2100 \mathrm{~K})$. Considerou-se, também, que o cristalizador e o suporte de cobre permanecem a $25^{\circ} \mathrm{C}$ durante toda a solidificação. Nesta simulação utilizou-se o método do $\mathrm{Cp}$ equivalente, o qual consiste em um método para solucionar problemas de transferência de calor transiente com mudança de fase [7]. Assume-se que tanto o processo de fusão como o processo de solidificação ocorre em um mesmo intervalo de temperatura $(T m-\Delta T, T m+\Delta T)$ ao invés de uma única temperatura de fusão, $T m$. Portanto, a temperatura varia de $T m-\Delta T$ para $T m+\Delta T$ quando o calor latente, $\Delta H_{f}$, é absorvido durante a mudança de fase do material na fusão [7]. Na simulação das tensões térmicas após a solidificação completa do lingote de silício, considerouse que no instante inicial da simulação, todo o lingote está à $1414^{\circ} \mathrm{C}$. Assumiu-se também, que não existe um contato perfeito entre a parede do lingote de silício e a parede do suporte de cobre e entre a parede do lingote de silício e a parede do cristalizador de cobre. Portanto, um coeficiente de transferência de calor de $1000 \mathrm{~W} /\left(\mathrm{m}^{2}{ }^{0} \mathrm{C}\right)$ foi adotado no contato entre as paredes do silício e do cobre.

\footnotetext{
* Contribuição técnica ao $69^{\circ}$ Congresso Anual da ABM - Internacional e ao 14ํㅡㄹ ENEMET - Encontro Nacional de Estudantes de Engenharia Metalúrgica, de Materiais e de Minas, 21 a 25 de julho de 2014, São Paulo, SP, Brasil.
} 


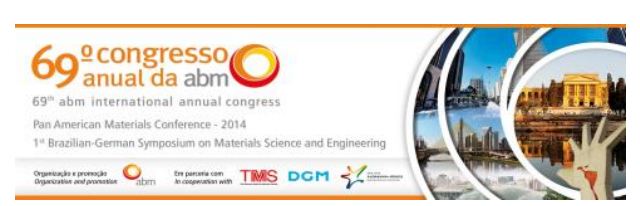

Considerou-se que a parede externa do cristalizador e que o fundo do suporte de cobre permanecem a $25^{\circ} \mathrm{C}$, devido à intensa refrigeração pela água dessas superfícies. Nesta simulação considera-se a transferência de calor no cristalizador e no suporte de cobre. As simulações foram realizadas no Abaqus 6.11 e utilizou-se 86.277 elementos do tipo C3D4T, que são elementos de quatro nós termicamente acoplados em um tetraedro com deslocamento e temperatura linear.

\section{RESULTADOS E DISCUSSÃO}

No lingotamento, todos os lingotes fraturam com o mesmo formato padrão da superfície de fratura e ficaram agarrados na parede do cristalizador. O comprimento dos lingotes variou entre 60 a $85 \mathrm{~mm}$. As imagens da Figura 4 resumem os resultados obtidos no lingotamento contínuo de silício. Observa-se na Figura 4 que as corridas em que a parede do cristalizador havia sido pintada com uma solução de nitreto de silício (corridas EB46, EB47 e EB48) não houve a fragmentação dos lingotes durante a remoção. Isso indica que a pintura da parede, fez com que o atrito entre as laterais dos lingotes e a parede do cristalizador diminuísse, possibilitando, assim, a remoção dos lingotes sem que ocorresse a fragmentação desses.

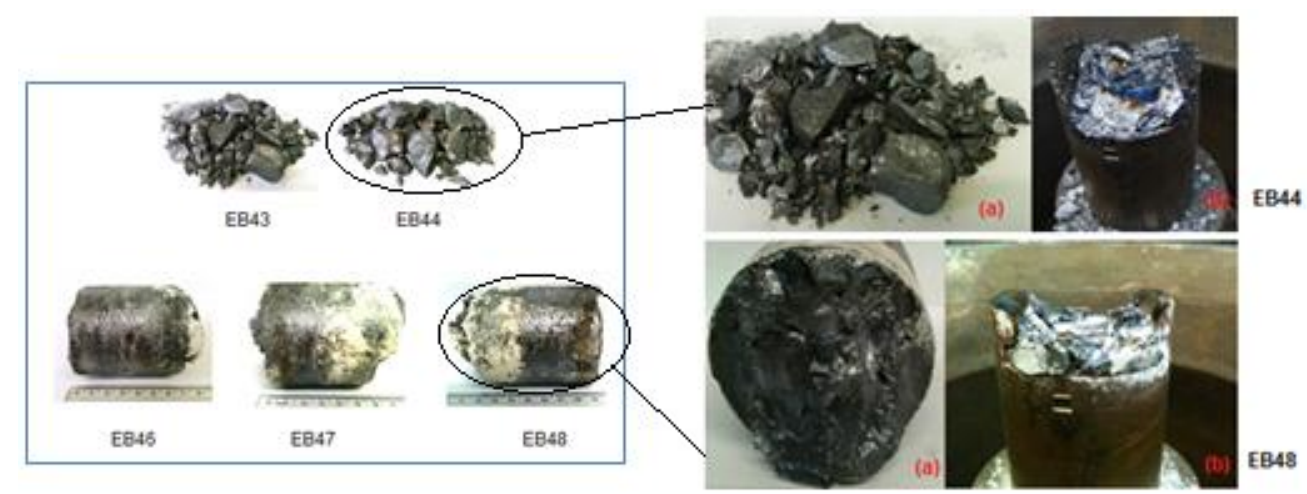

Figura 4. Sequência de resultados obtidos no lingotamento contínuo de silício (lado esquerdo). Resultado das corridas EB44 e EB48 (lado direito). (a) fragmentos do lingote EB44 e a região da fratura do lingote EB48. (b) Imagens do suporte de cobre com a outra parte fraturada dos lingotes, logo após o lingotamento contínuo.

$\mathrm{Na}$ Figura 4a, observam-se os fragmentos do lingote da corrida EB44 e a região da fratura do lingote EB48. A Figura $4 \mathrm{~b}$ mostra o suporte de cobre com restante do lingote EB44 e EB48, que fraturam durante o lingotamento contínuo. Nas imagens da Figura $4 \mathrm{~b}$ observa-se que a fratura do lingote no suporte de cobre é relativamente plana e que se localiza na borda superior dos braços do suporte de cobre. Ambas as superfícies de fratura possuem aspectos característicos de uma fratura frágil e um formato semelhante. Esse tipo de fratura relativamente plana, facetada, de aspecto brilhoso e localizada nas bordas superiores dos braços do suporte de cobre se repete sistematicamente em todos os lingotes, o que indica uma possível concentração de tensão localizada nas bordas superiores dos braços do suporte de cobre, capaz de levar sistematicamente à fratura frágil dos lingotes.

$\mathrm{Na}$ Figura 5a, observa-se que o calor foi extraído pelo fundo e pelas laterais do lingote. $O$ calor extraído pelo fundo produziu, no centro do lingote, agulhas verticais. Já o calor extraído pelas laterais do lingote tende a produzir, agulhas na direção horizontal. No entanto, nas proximidades da parede do lingote observam-se agulhas inclinadas ao invés de horizontais. Portanto, perto da parede do lingote, as duas

\footnotetext{
* Contribuição técnica ao $69^{\circ}$ Congresso Anual da ABM - Internacional e ao 14ํㅡㄹ ENEMET - Encontro Nacional de Estudantes de Engenharia Metalúrgica, de Materiais e de Minas, 21 a 25 de julho de 2014, São Paulo, SP, Brasil.
} 
direções de extração de calor devem ser consideradas. Isso indica que houve solidificação direcional apenas no centro do lingote.

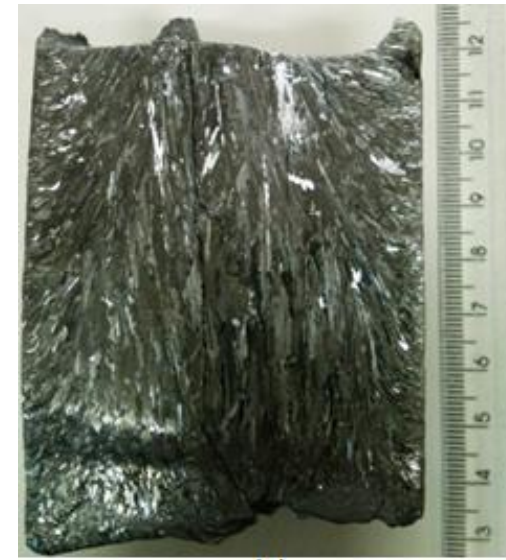

(a)

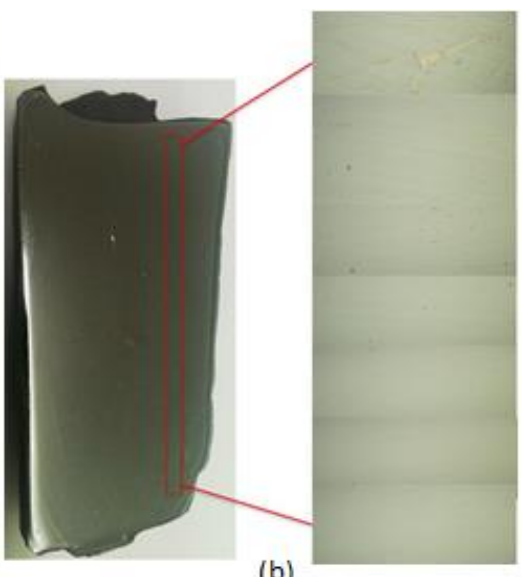

(b)

Figura 5. (a) Macrografia do lingote EB48. (b) Micrografia do lingote EB48 (aumento de 200x).

A observação longitudinal do lingote EB48 no microscópio ótico mostrou a ocorrência de refino por solidificação direcional (Figura 5b). O lingote EB48 foi produzido a partir de um iniciador de Si-GE, solidificado estaticamente sobre o suporte de cobre, antes do início do lingotamento contínuo. A alimentação durante o lingotamento contínuo foi feita com grânulos de Si-GM. Essa semente de Si-GE possuía em torno de $1 \mathrm{~cm}$ de altura o que corresponde a um nono do comprimento total do lingote EB48. Era esperado que se não houvesse refino por solidificação direcional, que uma quantidade razoável de impurezas se localizasse no centro do lingote. No entanto, isso não foi observado nas micrografias da Figura 5b, o que indicou a ocorrência de refino por solidificação direcional.

A Figura 6 mostra a superfície da fratura do lingote EB46 obtida no MEV por elétrons retroespalhados que permite observar as variações na composição da amostra. Regiões mais claras indicam a presença de elementos mais pesados, como cobre e ferro. Na Figura 6, observam-se marcas de rios e trincas que atravessam os contornos de grão, indicando que a propagação das trincas ocorreu por clivagem transgranular. Pode-se observar também, o ponto de origem de uma trinca em um contorno de grão.

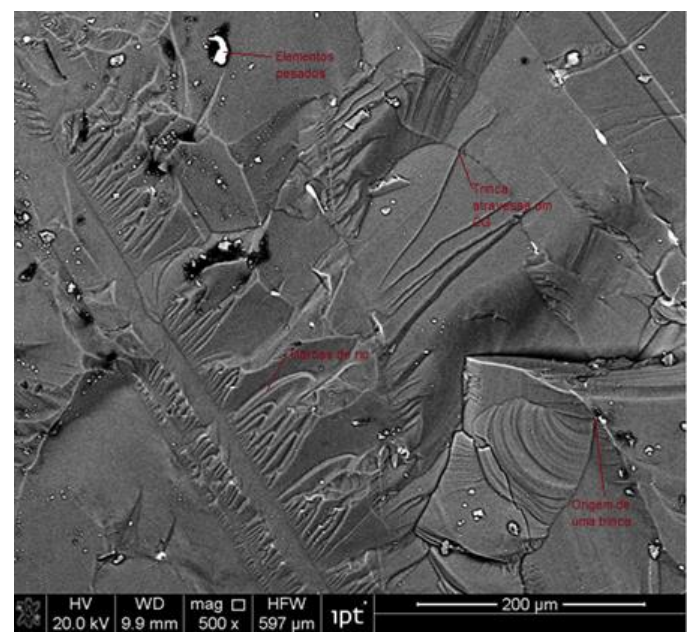

Figura 6. Imagens da superfície da fratura do lingote EB46 observada no MEV produzida por elétrons retroespalhados.

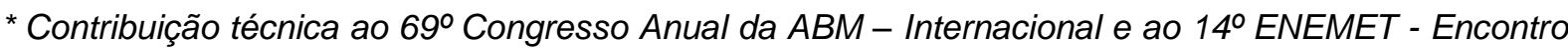
Nacional de Estudantes de Engenharia Metalúrgica, de Materiais e de Minas, 21 a 25 de julho de 2014, São Paulo, SP, Brasil.
} 


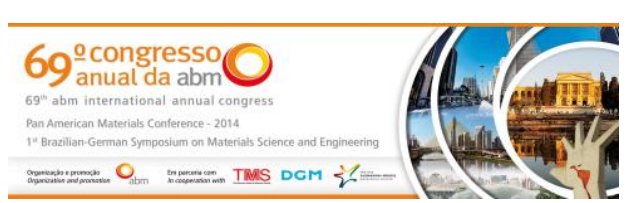

As Figuras 7 e 8 mostram as análises químicas obtidas por espectroscopia de energia dispersiva (EDS) dos pontos mais claros observados na Figura 6. Na Figura 7, o ponto analisado é composto principalmente por cobre. Trata-se, então, de uma impureza de cobre que pode indicar uma possível contaminação do lingote de silício pelo cobre do suporte. Na Figura 8, o ponto analisado é composto principalmente por ferro.
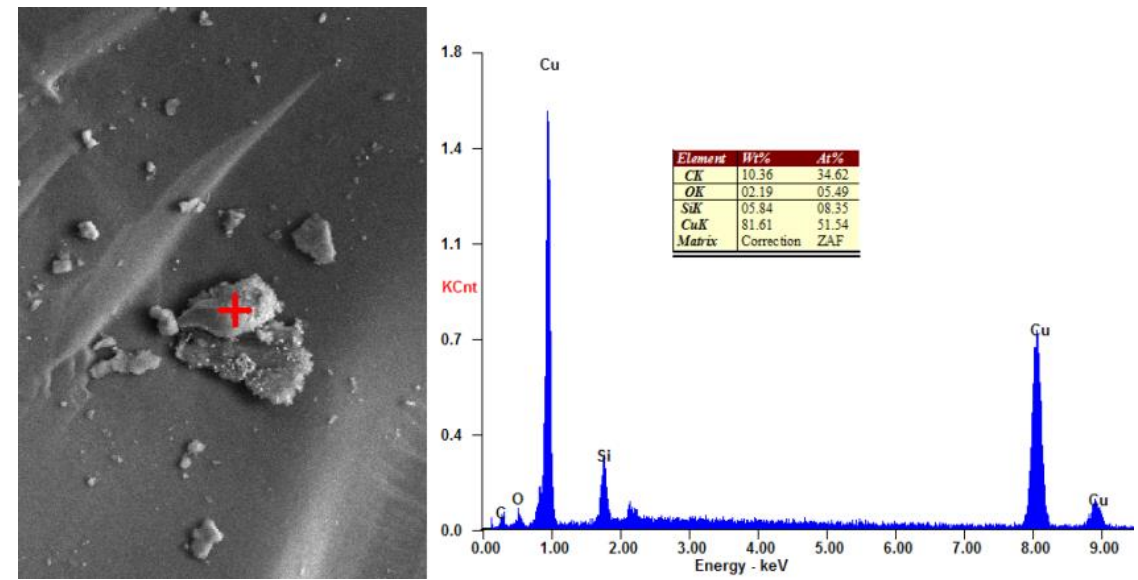

Figura 7. Análise química por EDS de um ponto mais claro observado na Figura 7. O resultado da análise química mostra que se trata de uma impureza de cobre. Aumento de 1000x.

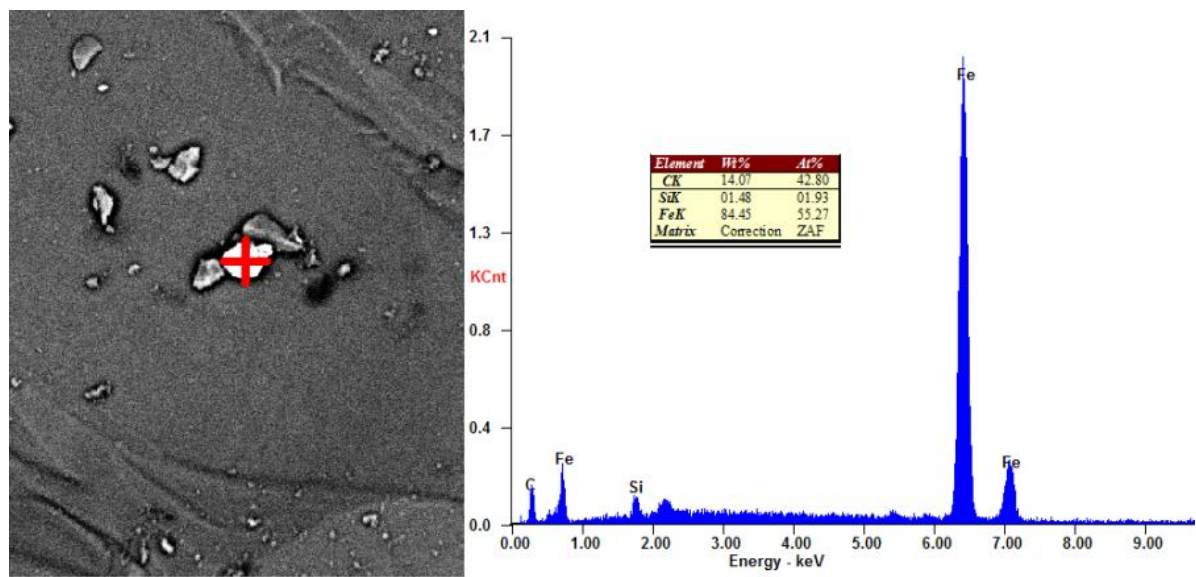

Figura 8. Análise química por EDS de um ponto mais claro observado na Figura 7. O resultado da análise química mostra que se trata de uma impureza de ferro. Aumento de 1000x.

A Tabela 2 mostra a composição inicial do Si-GM utilizado no lingotamento contínuo e os resultados da análise química por ICP-OES dos fragmentos da corrida EB43 e EB44.

Tabela 2. Análise química dos lingotes

\begin{tabular}{|l|l|l|l|l|l|}
\hline Corrida & $\begin{array}{l}\text { Potencia do } \\
\text { feixe (W) }\end{array}$ & $\begin{array}{l}\text { Tempo } \\
\text { Operação } \\
(\mathbf{m i n})\end{array}$ & $\begin{array}{l}\mathbf{P}(\mathbf{p p m}) \\
(36 \pm 6 \mathrm{ppm})^{*}\end{array}$ & $\begin{array}{l}\text { Cu (ppm) } \\
(4 \pm 2 \text { ppm })^{*}\end{array}$ & $\begin{array}{l}\mathbf{F e}(\mathbf{p p m}) \\
(1600 \pm 400 \mathrm{ppm})^{*}\end{array}$ \\
\hline EB43 & 20 & 18 & $31 \pm 2$ & $178 \pm 86$ & $393 \pm 179$ \\
\hline EB44 & 20 & 6 & $31 \pm 5$ & $228 \pm 143$ & $523 \pm 194$ \\
\hline
\end{tabular}

Observa-se na Tabela 2, uma pequena remoção de fósforo por destilação no vácuo durante o lingotamento contínuo, a ocorrência de uma considerável contaminação do lingote de silício por cobre e uma diminuição na concentração de ferro. O contato do lingote com o suporte de cobre e com as paredes do cristalizador durante 0

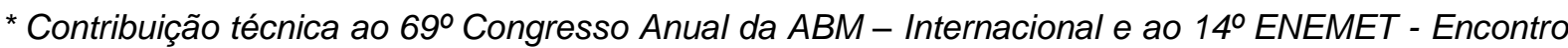
Nacional de Estudantes de Engenharia Metalúrgica, de Materiais e de Minas, 21 a 25 de julho de 2014, São Paulo, SP, Brasil.
} 


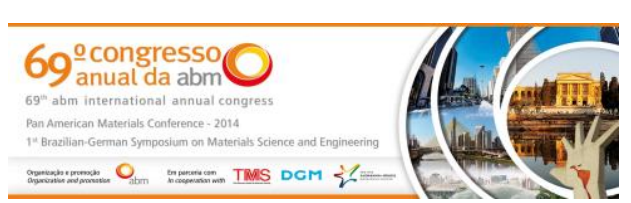

processo de lingotamento ocasionou a contaminação por cobre. Já a pequena remoção de fósforo se deve ao baixo tempo de exposição do material ao feixe de elétrons, ocasionada pelo deslocamento do suporte de cobre durante o lingotamento contínuo. A diminuição da concentração de ferro se deve ao refino por solidificação direcional, pois a pressão de vapor do ferro está muito próxima à pressão de vapor do silício e o coeficiente de partição no equilíbrio do ferro no silício líquido é $4,2 \times 10^{-6}$ $\left(\sim 1414^{\circ} \mathrm{C}\right)$ [1]. Isso significa que para remover ferro por evaporação seria necessário remover uma quantidade significativa de silício, o que não ocorre. Entretanto, o baixo valor do coeficiente de partição do ferro no silício líquido indica que a concentração de impureza no sólido é muito menor que a concentração de impurezas na fase líquida. Portanto, o refino de silício em relação ao ferro se dá muito provavelmente pela segregação de ferro para a fase líquida durante a solidificação direcional.

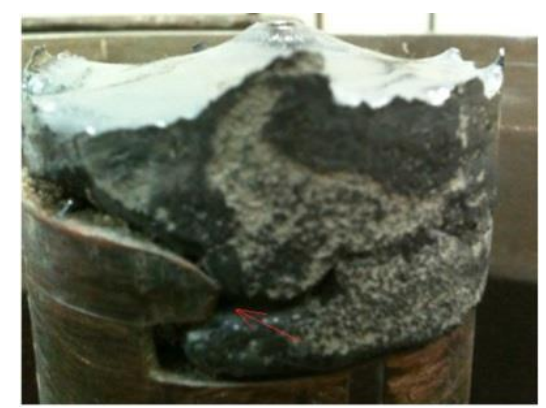

Figura 9. Iniciador de silício solidificado sobre o suporte de cobre.

Na Figura 9, observa-se a fratura de um iniciador de Si-GE solidificado sobre o suporte de cobre. A fratura está indicada pela seta vermelha e ocorreu na mesma região da fratura do lingote de silício durante o lingotamento contínuo. Isso indica as tensões térmicas originadas pelos gradientes térmicos após a solidificação são suficientes para fraturar o material.

\subsection{Resultado das Simulações}

A Tabela apresenta os parâmetros utilizados nas simulações.

Tabela 3. Parâmetros utilizados nas simulações

\begin{tabular}{|c|c|c|}
\hline \multicolumn{3}{|l|}{ Parâmetros da simulação } \\
\hline & Cobre & Silício \\
\hline Temperatura de Fusão $\left({ }^{0} \mathrm{C}\right)$ & 1085 & 1414 \\
\hline Entalpia de fusão ou calor latente, $\Delta H_{f}(\mathrm{~J} / \mathrm{g})$. & 472 & $1787[8]$ \\
\hline Condutividade térmica $\left(\mathrm{W} / \mathrm{m} .{ }^{0} \mathrm{C}\right)$ & 398 & $\mathrm{k}\left(\mathrm{T} /{ }^{0} \mathrm{C}\right)=58.2+2.5 \times 10^{-2}(\mathrm{~T}-1414)[8]$ \\
\hline Condutividade térmica no sólido, $\mathrm{ks}\left(\mathrm{W} / \mathrm{m} .{ }^{0} \mathrm{C}\right)$ & ----------- & $141[8]$ \\
\hline Condutividade térmica no líquido, $\mathrm{kl}\left(\mathrm{W} / \mathrm{m} .{ }^{\circ} \mathrm{C}\right)$ & ----------- & $58,2[8]$ \\
\hline Densidade $\left(\mathrm{kg} / \mathrm{m}^{3}\right)$ & 8920 & $\rho\left(\mathrm{T} /{ }^{0} \mathrm{C}\right)=2560-0.30(\mathrm{~T}-\mathrm{Tm})[8]$ \\
\hline Módulo de Young, E (GPa) & 128 & $E(T / 0 C)=-9 \times 10^{-7} T^{2}-0.0026 T+118.41[9]$ \\
\hline Calor específico $\left(\mathrm{J} / \mathrm{kg}^{0} \mathrm{C}\right)$ & 386 & $\left.C_{p}\left(T /{ }^{0} \mathrm{C}\right)=-2 \times 10^{-4} \mathrm{~T}^{2}+0.4 \mathrm{~T}+723,2\right)[8]$ \\
\hline Calor específico no sólido, $\mathrm{C}_{p s}\left(\mathrm{~J} / \mathrm{kg}^{0} \mathrm{C}\right)$ & --------- & $0,712[8]$ \\
\hline Calor específico no líquido, $\mathrm{C}_{\mathrm{pl}}\left(\mathrm{J} / \mathrm{kg}^{0} \mathrm{C}\right)$ & --------- & $0,968[8]$ \\
\hline Intervalo de temperatura, $\Delta \mathrm{T}\left({ }^{\circ} \mathrm{C}\right)$ & ---------- & 50 \\
\hline Coeficiente de expansão térmica, $\theta\left({ }^{0} \mathrm{C}^{-1}\right)$ & $1,7 \times 10^{-5}$ & $=-2 \times 10^{-6} T^{2}+0.0036 T+2.7901$ \\
\hline
\end{tabular}

A Figura 10 mostra a evolução da temperatura do silício com o tempo, em um corte no plano $\mathrm{XY}$, transversal aos braços do suporte de cobre, localizado no centro do

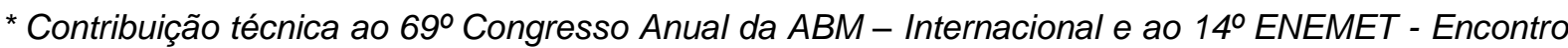
Nacional de Estudantes de Engenharia Metalúrgica, de Materiais e de Minas, 21 a 25 de julho de 2014, São Paulo, SP, Brasil.
} 


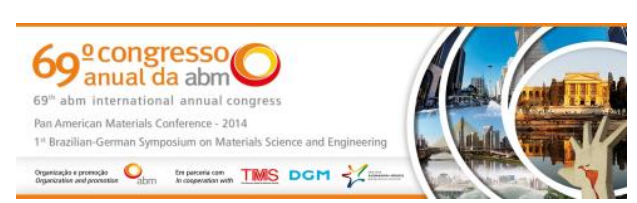

desenho. No tempo $\mathrm{t}=0$, o silício está totalmente fundido a uma temperatura de $2100^{\circ} \mathrm{C}$. No tempo $\mathrm{t}=30 \mathrm{~s}$, todo o iniciador está a aproximadamente $1754^{\circ} \mathrm{C}$. No tempo $t=49 \mathrm{~s}$, observa-se a formação de uma casca sólida na parede do iniciador, com exceção da região da borda dos braços do suporte de cobre. Na Figura 11, observa-se que todo o iniciador está solidificado e que o tempo total de solidificação foi de aproximadamente 50 segundos.
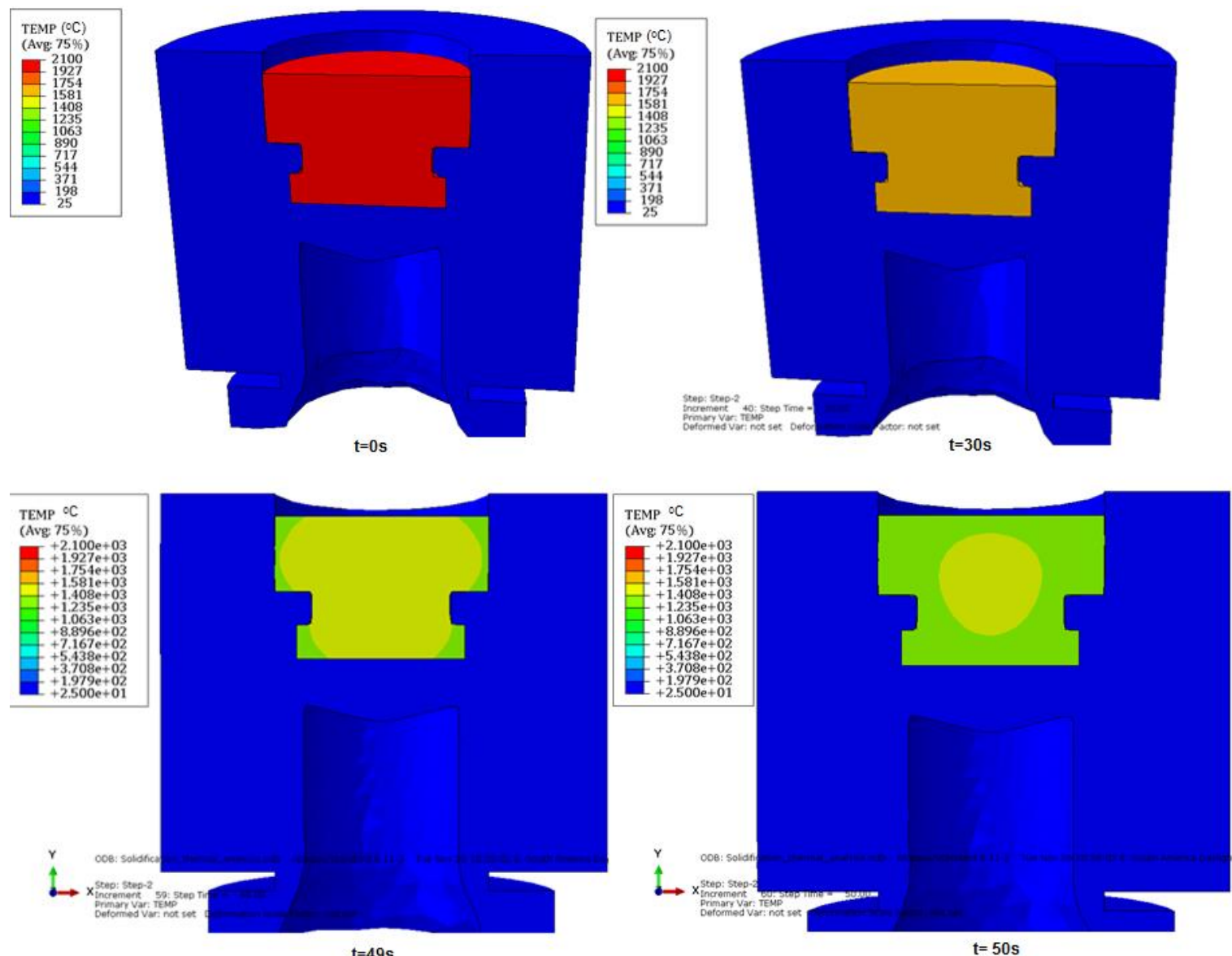

Figura 10. Mostra a evolução da temperatura do silício com o tempo, em um corte no plano $X Y$, transversal aos braços do suporte de cobre, localizado no centro do desenho do sistema: lingote, suporte e cristalizador.

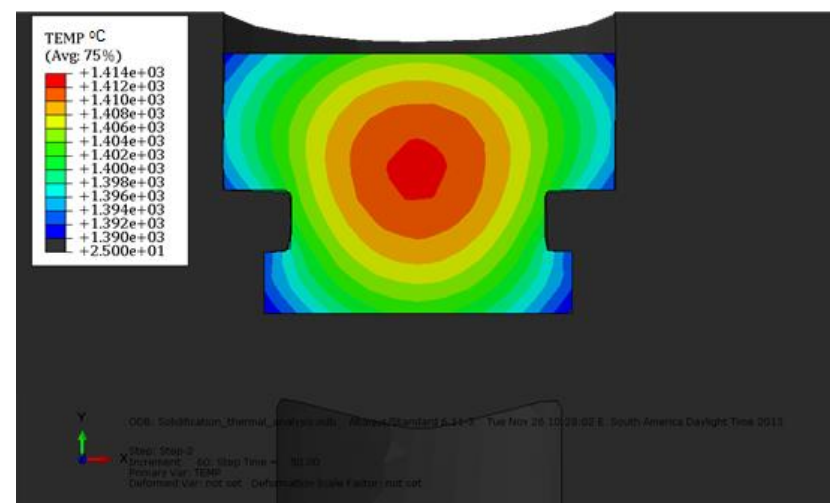

Figura 11. Tempo $t=50$ s na simulação da evolução da temperatura na solidificação de um iniciador de silício. Imagem para um intervalo de temperatura de 1414 a $1390{ }^{\circ} \mathrm{C}$.

As Figuras 12a e 12b mostram respectivamente a distribuição de temperatura e as tensões térmicas para um tempo de 1,3 segundos, através de um corte no plano YZ

* Contribuição técnica ao $69^{\circ}$ Congresso Anual da ABM - Internacional e ao 14ํㅡㄹ ENEMET - Encontro Nacional de Estudantes de Engenharia Metalúrgica, de Materiais e de Minas, 21 a 25 de julho de 2014, São Paulo, SP, Brasil. 


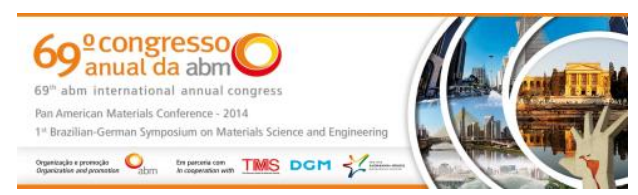

paralelo às bordas dos braços do suporte de cobre, deslocado do centro do desenho. $\mathrm{Na}$ Figura 12a, observa-se no fundo do lingote, a transição do comportamento dúctil para frágil. Na Figura 12b, observa-se a máxima tensão obtida na simulação das tensões térmicas após a solidificação do lingote. Ela está localizada perto da borda superior de um dos braços do suporte de cobre. O valor é aproximadamente 1,2GPa. Segundo o critério de Rankine, as tensões principais no estado de tensões analisado não podem ser iguais ou maiores que a máxima tensão normal encontrada para o material em ensaios uniaxiais de tração. Se as tensões térmicas normais ao plano XZ (Figura 12b) corresponderem às tensões principais de tração e se o limite de resistência à fratura ( 1,0GPa) corresponder à tensão máxima normal obtida em um ensaio de tração, pode-se afirmar que o material irá falhar sob uma tensão de 1,2GPa nas proximidades das bordas superiores dos braços do suporte de cobre. Esse resultado obtido pela simulação das tensões térmicas foi confirmado pela análise da fratura dos lingotes.

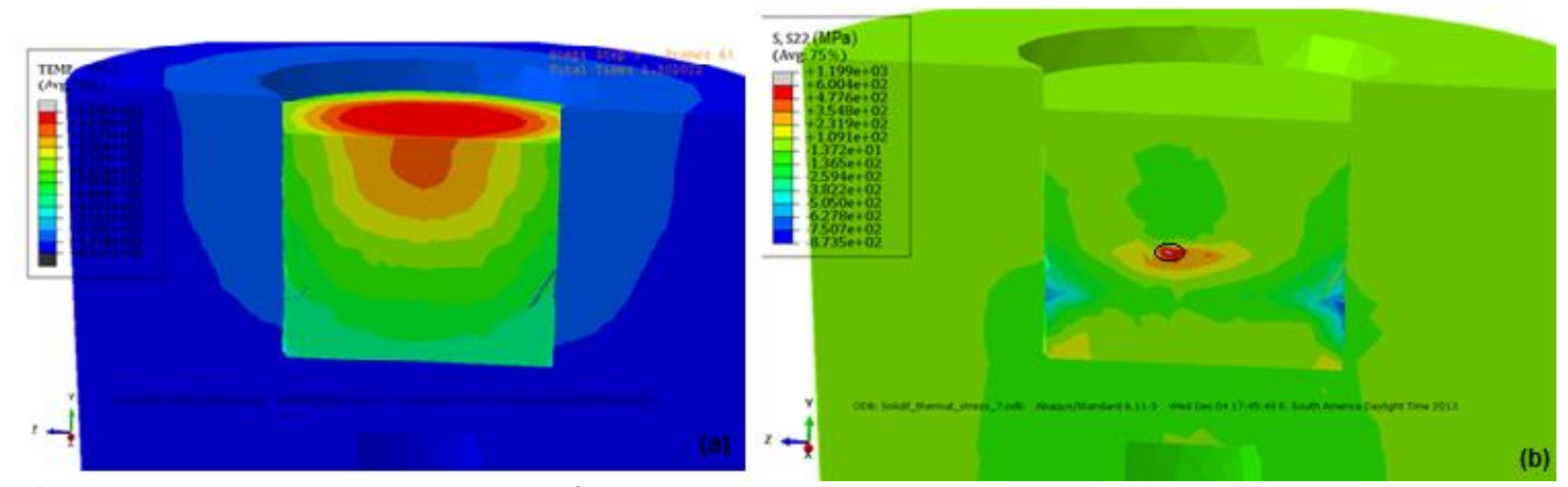

Figura 12. Um corte no plano YZ próximo das bordas dos braços do suporte de cobre no tempo de 1,3 segundos após a solidificação do lingote. (a) Distribuição de temperatura (b) Distribuição das tensões térmicas normais ao plano XZ. A região circulada indica a máxima tensão $(1,2 \mathrm{GPa})$.

\section{CONCLUSÕES}

Pode-se concluir, neste trabalho, que a pintura da parede do cristalizador com uma solução de $\mathrm{Si}_{3} \mathrm{~N}_{4}$ diminuiu o atrito com a parede dos lingotes de silício, facilitando a remoção sem que ocorresse a fragmentação desses. Sem exceção, os lingotes tiveram uma fratura relativamente plana, facetada, de aspecto brilhoso e localizada nas bordas superiores dos braços do suporte de cobre. Isso significa que existe uma concentração de tensão nos lingotes de silício localizada nas bordas superiores dos braços do suporte de cobre, capaz de levar sistematicamente à fratura frágil desses, após a solidificação. A fratura frágil ocorre por clivagem transgranular. Através da macrografia do lingote da corrida EB48, conclui-se que no centro do lingote, o calor foi extraído preferencialmente pelo fundo e que apenas nessa região ocorre solidificação direcional. A análise das micrografias do lingote da corrida EB48 e a análise química dos fragmentos das corridas EB43 e EB44 confirmaram a ocorrência de refino por solidificação direcional de impurezas metálicas, principalmente de ferro. A análise química também indicou uma significativa contaminação por cobre, ocasionada pelo contato do suporte de cobre com o lingote, e uma pequena remoção de fósforo por evaporação. Para que haja uma significativa remoção de fósforo por evaporação será necessário que a velocidade de deslocamento do suporte de cobre durante o lingotamento contínuo seja reduzida.

\footnotetext{
* Contribuição técnica ao $69^{\circ}$ Congresso Anual da ABM - Internacional e ao 14ํㅡㄹ ENEMET - Encontro Nacional de Estudantes de Engenharia Metalúrgica, de Materiais e de Minas, 21 a 25 de julho de 2014, São Paulo, SP, Brasil.
} 
